\title{
Trough Concentration Divided by Body Mass Index
}

National Cancer Institute

\section{Source}

National Cancer Institute. Trough Concentration Divided by Body Mass Index. NCI

Thesaurus. Code C102395.

The trough concentration divided by body mass index. 